EGU2020-149

EGU General Assembly 2020

(c) Author(s) 2019. This work is distributed under

the Creative Commons Attribution 4.0 License.

\title{
How isostasy explains continental rifting in East Africa?
}

\author{
Mohammad Bagherbandi ${ }^{1,2}$ and Nureldin A. A. Gido ${ }^{2}$ \\ ${ }^{1}$ Faculty of Engineering and Sustainable Development, University of Gävle, Gävle, Sweden (modbai@hig.se) \\ ${ }^{2}$ Division of Geodesy and satellite positioning, Royal Institute of Technology (KTH), SE-10044 Stockholm, Sweden
}

The principle of isostasy plays an important role to understand the relation between different geodynamic processes. Although, it is difficult to find an exact method that delivers a complete image of the Earth structure. However, gravimetric methods are alternative to provide images of the interior of the Earth. The Earth's crust parameters, i.e. crustal depth and crust-mantle density contrast, can reveal adequate information about the solid Earth system such as volcanic activity, earthquake and continental rifting. Hence, in this study, a combine Moho model using seismic and gravity data is determined to investigate the relationship between the isostatic state of the lithosphere and seismic activities in East Africa. Our results show that isostatic equilibrium and compensation states are closely correlated to the seismicity patterns in the study area. For example, several studies suggest that African superplume causes the rift valley, and consequently differences in crustal and mantle densities occur. This paper presents a method to determine the crustal thickness and crust-mantle density contrast and consequently one can observe low-density contrast (about $200 \mathrm{~kg} / \mathrm{m}^{3}$ ) and thin crust (about $30 \mathrm{~km}$ ) near the triple junction plate tectonics in East Africa (Afar Triangle), which confirms the state of overcompensation in the rift valley areas. Furthermore, the density structure of the lithosphere shows a large correlation with the earthquake activity, sub-crustal stress and volcanic distribution across East Africa. 